American Journal of Applied Sciences 5 (11): 1547-1551, 2008

ISSN 1546-9239

(C) 2008 Science Publications

\title{
Boundary Shear Stress around Bridge Piers
}

\author{
Mirali Mohammadi \\ Department of Civil Engineering, Faculty of Engineering, \\ The University of Urmia, P.O. Box 165, Urmia 57169-33111, Iran
}

\begin{abstract}
This research presents the measurement of boundary shear stress around the base of some elliptical shaped bridge piers using Preston tube technique. The uniform flow was established and a series of measurements having different discharges and channel bed slopes were undertaken. General results are established and then the effects of flow separation on the hydraulic theory are assessed. The Analysis of results shows that behind the bridge piers (horseshoe area); the amount of boundary shear stress reduces dramatically. The figure for the rate of boundary shear stress of nose to end is about $\tau_{\mathrm{r}}=\tau_{\mathrm{n}} / \tau_{\mathrm{e}}=3$.6. It has a remarkable reduction even in steep slopes. The bed shear stress was found to intensify near the nose of the piers. The distribution of boundary shear stress in both mild and steep channel bed slopes along spanwise direction is presented that may give a valuable perspective of the flow action around piers.
\end{abstract}

Key words: shear stress, bridge pier, Preston tube, horseshoe area, open channel.

\section{INTRODUCTION}

In engineering design and safety, the effects of alluvial river flow around a bridge pier is an important practical problem. Scour and deposition of bed load sediment material around bridge piers can lead to make erosion at the piers foundation and eventually structural collapses of the bridge. This process is driven by the transport of bed load sediment in appearance of the pier. The classical theory of open channel flows may had such considerable success in describing of the unsteady evolution of bed form structures in one dimensional river channels both through analytical and computational approaches ${ }^{[1,4,6,17,18,20]}$. The writer believes that the problem of scouring and deposition processes may have a close relationship with boundary shear stress around bridge piers. However, some researchers have used the alluvial hydraulics theory to examine the process ${ }^{[13]}$. In their review paper, Breusers et $a l .^{[3]}$ summarize the experimental and observations work on the processes of scour and deposition due to water flow around bridge piers established by other researchers ${ }^{[19]}$.

It has already been well established that depending upon the bridge pier types and flow condition, the structure of flow may be composed of any, all or none of the vortex systems namely horseshoe, wake and trailing. If none of horseshoe and trailing occurs the flow remains attached to the pier, without separation in either the horizontal or vertical planes. A horseshoe vortex system is generated by initial separation of the bottom boundary into the vertical plane upstream of the pier. When the horseshoe system is not dominant but the separation of the boundary layer attached to the pier occurs on the downstream side of the pier, leading to the presence of shear layers in the horizontal plane, a wake vortex system occurs. When the temporal instability appears in wake system, a trailing vortex system is generated.

According to Breusers et $a l^{[3]}$ in flows include wake and trailing vortex systems or which are without separation, at the upstream end of the pier the main scouring dose not take place longer, but down the side and to the rear of the pier. Therefore the dynamics of bridge pier scour is strongly related to the presence or absence of vortex system. However, this phenomenon depends upon the geometry as well as aspect ratio of the bridge piers. For example, for low aspect ratios, streamlined piers, the effect of horseshoe vortex is weak and it may be expected that essentially irrotational hydraulic effects drive the scour and deposition phenomenon at the piers foundation. Using the salient features reported by Breusers et al. ${ }^{[3]}$. Needham and Zanre $^{[13]}$ developed a 2D mathematical alluvial hydraulic theory to investigate the dynamics of alluvial flows around bridge piers. Nevertheless, they conclude that their theory itself at least quantitatively accounts for the mechanism of scour for piers in which the horseshoe vortex system is relatively weak. It is important to notice that the general 3D flow structures that exist in straight or curved prismatic channels including bridge piers, in order to understand the lateral 
distribution of boundary shear stress. The distributions are well established by reference to the governing equations and illustrative sketches.

\section{DESCRIPTION OF EXPERIMENTAL APPARATUS AND PROCEDURE}

The experiments were carried out under uniform flow condition in a $6 \mathrm{~m}$ (workable) long glass-walled rigid tilting flume with a working cross section of $1 \mathrm{~m}$ wide and $0.6 \mathrm{~m}$ deep. The flume is supported by a hydraulic jack and rotated about a hinge joint beneath about the middle of the channel. The flume also had a motorized slope control with a mechanical visual read out on a ruler at the upstream end used to set the precise channel bed slope. The experimental three bridge piers having elliptical section placed in the flow direction inside the channel with equal distances. Water was supplied to the channel by an overhead tank through 8 inches diameter pipeline for discharges up to $100 \mathrm{l} / \mathrm{s}$. To reduce large-scale disturbances and in order to ensure that the flow is uniformly distributed, two netted plates were placed at the upstream of the channel where the entrance tank and bell-mouth shaped inlet transition section was located. However, for the case of supercritical flows i.e. Fr $>1$ this system is not very useful. Discharge measurements were made by means of a V-notch spillway system placed at the end of downstream tank. Using a pointer gauge the water level was read from a well connected to the tank. A calibration equation produced by Movahedan ${ }^{[12]}$ and double-checked by the author, was used for estimating discharges through the $\mathrm{V}$-notch. A tailgate weir was installed in the downstream end of the channel in order to minimize upstream disturbance of the flow and hence allowed a greater reach of the channel to be employed for experimental measurement in sub critical flows.

The test section consisted $5 \mathrm{~m}$ long, commencing at a distance of $4.3 \mathrm{~m}$ from the channel bell mouth entrance and $2.2 \mathrm{~m}$ from tailgate. On the other hand, for supercritical flows, because of developing S2 profiles the test length was reduced to about $4 \mathrm{~m}$. A trolley was mounted on rails running along the flume with a depth probe and a bar with a Preston tube. A tabloid of piezometers connected to the tapping holes at the beneath channel bed having $15 \mathrm{~cm}$ distance from each other was also used to establish uniform flow and hence the flow depth was obtained. The channel bed slope set by stilling water level on the channel before any experimental run. Five bed slopes of 0.001, 0.002, 0.004, 0.009 and 0.016 were selected for experimental purposes. A mesh of measurement points $(6 \mathrm{~cm} \times 6 \mathrm{~cm})$ was drawn inside the channel bed around bridge piers

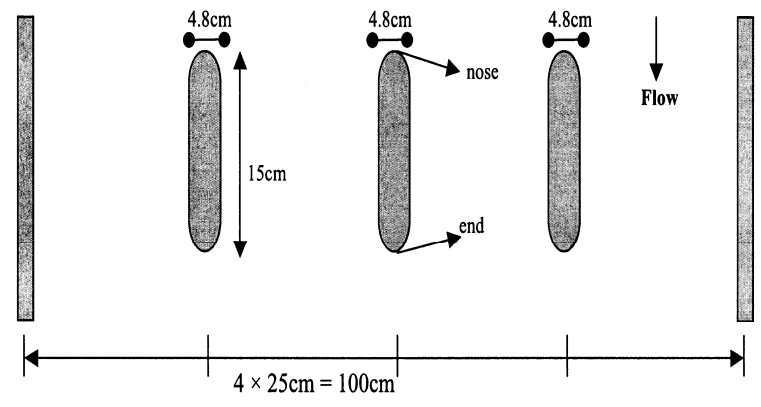

Fig. 1: The schematic Figure for the position of bridge piers placed inside the channel

(including $10 \mathrm{~cm}$ upper nose and $30 \mathrm{~cm}$ after downstream end of piers). Experimental elliptical piers have the same dimension of $4.8 \mathrm{~cm}$ width $\times 15 \mathrm{~cm}$ length $\times 50 \mathrm{~cm}$ height Fig. 1 .

\section{BOUNDARY SHEAR STRESS MEASUREMENTS AND ASSESSMENT OF ITS VALUES}

Preston $^{[16]}$ developed a simple technique for measuring local boundary shear stress on smooth surfaces in a turbulent boundary layer using a Pitot tube in contact with the bed/wall surface. The basis of this method is on the assumption of the inner velocity law (law of the wall), relating boundary shear stress to the velocity distribution near the wall. Using the pressure drop in a pipe to calibrate the instrument, Preston obtained equations relating shear to the difference between stagnation point (Pitot tube) and static pressure reading. Ensuing research by Bradshaw and Gregory ${ }^{[2]}$, cast doubt on the applicability and accuracy of the Preston method. However Patel ${ }^{[14]}$ has undertaken further experiments to produce a reliable and definitive calibration curve for the Preston tube, which is now universally accepted. In present research study, the local boundary shear stress was measured using the Preston tube technique with a probe of $4.7 \mathrm{~mm}$ outer diameter. The tube was mounted on a carriage and aligned vertically near the walls and normal to the bed. The tube was placed on the channel boundary every determinate intervals on the vertical walls and on the channel bed in span wise direction. The total pressure arising from the difference between the static and dynamic pressures were recorded by connecting the tubes to a simple manometer inclined at $12.5^{\circ}$ to the horizontal. Dynamic pressures were then converted to the local boundary shear stress using the Patel ${ }^{[14]}$ calibration equations. He developed the two dimensionless parameters given by: 


$$
\mathrm{X}^{*}=\log \left(\frac{\Delta \mathrm{Pd}}{4 \rho v^{2}}\right) ; \quad \mathrm{z}^{*}=\log \left(\frac{\tau \mathrm{d}^{2}}{4 \rho v^{2}}\right)
$$

where, $\mathrm{z}^{*}<1.5$

$$
\mathrm{z}^{*}=0.5 \mathrm{x} *+0.037
$$

$1.5<z^{*}<3.5$

$$
\begin{aligned}
\mathrm{z}^{*}= & -0.006 \mathrm{x} *^{3}+0.1437 \mathrm{x} *^{2} \\
& -0.1381 \mathrm{x} *+0.8287
\end{aligned}
$$

$\mathrm{z}^{*}>3.5$

$$
\mathrm{x}^{*}=\mathrm{z}^{*}+2 \log (1.95 \mathrm{z} *+4.10)
$$

in which $\mathrm{P}$ is the pressure, $\mathrm{d}$ is the Preston brass tube outer diameter, $\rho$ is the water density, $v$ is the kinematics viscosity and $\tau$ is the bed shear stress.

\section{RESULTS AND DISCUSSION}

To investigate the hydraulic characteristics of a rectangular channel including three bridge piers inside, several series of experiments were conducted for measuring boundary shear stress around the piers, especially upstream (nose) and downstream (end) of the piers. For a certain channel bed slope, a discharge was introduced and uniform flow was established using discharge-tailgate relationships. For every set of flows dynamic pressure in contact with channel boundary were measured. The data are analyzed from a variety of different perspectives and the results from each analysis are used to interpret the mechanics occurring in the flow. The findings from each perspective complement each other and highlight the consistency of the experimental data. The lateral distribution results are separated in two channel cases of mild and steep slopes explained as follows.

Mild slope channels: Several flow conditions are examined in this case. For example, Fig. 2 and 3 show the boundary shear stress distributions along channel width around the piers basis for two selected flow rates and channel bed slopes of $\mathrm{Q}=25.46 \mathrm{l} / \mathrm{s}$ and $\mathrm{S}_{0}=0.002$ and $\mathrm{Q}=52.32 \mathrm{l} / \mathrm{s}$ and $\mathrm{S}_{0}=0.004$. In all Figures $\mathrm{y}=\mathrm{A}$, $\mathrm{B}, \ldots \ldots \mathrm{K}$ refers to the selected points on the mesh at the bed along channel width and around bridge piers.

In the mild slope condition the Froude numbers are less than 1.0 and consequently the flows are in sub critical conditions. As can be seen from those Figures,

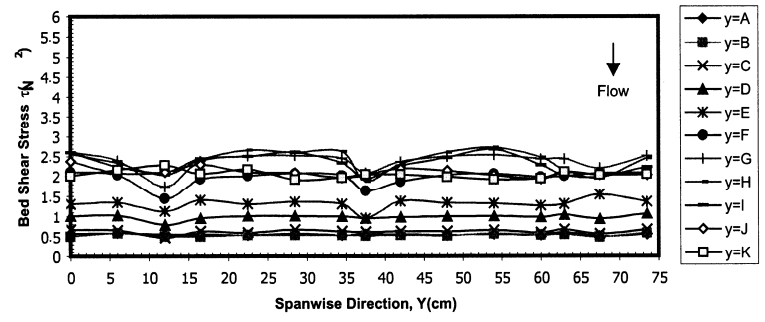

Fig. 2: Spanwise local bed shear Stress distribution around bridge piers $\left(\mathrm{Q}=25.46 \mathrm{l} / \mathrm{s} ; \mathrm{S}_{0}=0.002\right)$

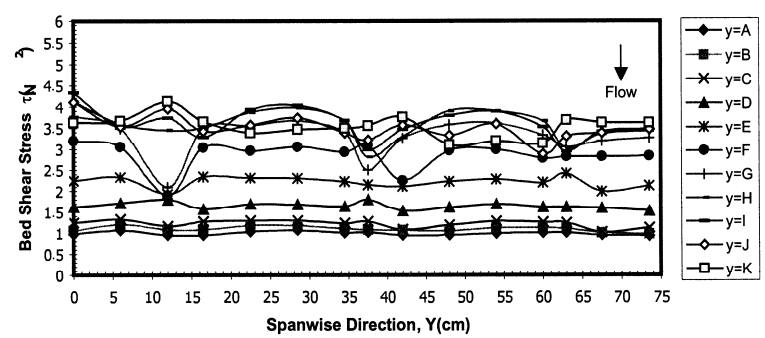

Fig. 3: Spanwise local bed shear Stress distribution around bridge piers $\left(\mathrm{Q}=52.32 \mathrm{l} / \mathrm{s} ; \mathrm{S}_{0}=0.004\right)$

Table 1: Experimental data and results.

\begin{tabular}{lllll}
\hline $\mathrm{S}_{0}$ & $\mathrm{Q}\left(\mathrm{ls}^{-1}\right)$ & $\tau_{\mathrm{n}}\left(\mathrm{N} \mathrm{m}^{-2}\right)$ & $\tau_{\mathrm{e}}\left(\mathrm{N} \mathrm{m}^{-2}\right)$ & $\tau_{\mathrm{r}}=\tau_{\mathrm{n}} / \tau_{\mathrm{e}}$ \\
\hline 0.001 & 87.55 & 4.88 & 1.30 & 3.76 \\
0.002 & 25.46 & 2.24 & 0.53 & 4.25 \\
0.004 & 25.16 & 2.35 & 0.73 & 3.19 \\
0.004 & 52.32 & 3.66 & 0.98 & 3.74 \\
0.004 & 85.67 & 4.63 & 1.26 & 3.66 \\
0.009 & 50.15 & 3.36 & 1.03 & 3.27 \\
0.009 & 88.82 & 4.63 & 1.34 & 3.45 \\
0.016 & 55.17 & 4.65 & 3.57 & 1.30 \\
& & & & Ave. $=3.61$ \\
\hline
\end{tabular}

the distributions are fairly flat along the span wise direction. However around the piers, the perturbations begin to appear. This is because the aspect ratio changes and therefore the cross sectional shape and secondary flow cells size or perhaps number of cells influence the flow behavior. The maximum value of bed shear stress tends to occur at the nose of pier base. The minimum values of bed shear stress belong to the end edge of the piers base where the horseshoe vortex and flow separation area occurs. Table 1 illustrates the averaged rate of bed shear stress at nose to end of piers. It can be seen that the figure is about $\tau_{\mathrm{r}}=3.6$.

Steep slope channels: Different flow conditions are also examined in steep channels. Figure 4 and 5 illustrate the boundary shear stress distributions along channel width around the piers basis for some selected flow discharges and channel bed slopes i.e. $\mathrm{Q}=50.15$ $1 / \mathrm{s} \quad \& \mathrm{~S}_{0}=0.009$ and $\mathrm{Q}=55.17 \mathrm{l} / \mathrm{s} \quad \& \mathrm{~S}_{0}=0.016$. 


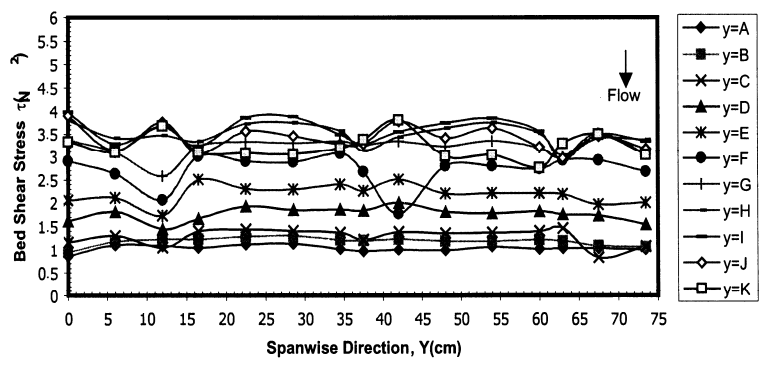

Fig. 4: Spanwise local bed shear Stress distribution around bridge piers $\left(\mathrm{Q}=50.15 \mathrm{l} / \mathrm{s} ; \mathrm{S}_{0}=0.009\right)$

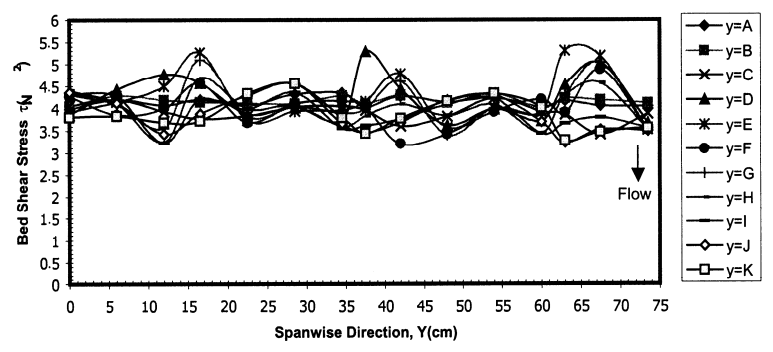

Fig. 5: Spanwise local bed shear Stress distribution around bridge piers $\left(\mathrm{Q}=55.17 \mathrm{l} / \mathrm{s}, \mathrm{S}_{0}=0.016\right)$

In a case of higher Froude numbers i.e., steeper channels and even large flow discharges, there are more severe perturbations in the distributions. There is also a significant variation of boundary shear stress across the channel, especially at high Froude numbers or large flow rates in steeper channels Fig. 5. The perturbations in this Figure may indicate the size and number of the secondary flow cells as suggested by researchers ${ }^{[5,7,8,9,11,15]}$ and others for open channel flows. This leads to a view that for a certain flow depth, as the channel gets steeper, the number of secondary flow cells are more than those for a mild slope, thus the situation of horseshoe area becomes more sensible, however the size of the cells for mild slope channels are bigger than that of the steeper ones. This phenomenon plays an important role in the sediment-laden channels including bridge piers where the channel section is even contracted. It also affects the incipient motion of the sediment particles described by Mohammadi and Knight $^{[10]}$ and Mohammadi ${ }^{[7]}$.

\section{CONCLUSIONS}

Using the Preston tube technique, boundary shear stress measurements have been undertaken in the fully developed uniform flow condition for three target flow discharges $(\mathrm{Q}=25,50$ and $85 \mathrm{l} / \mathrm{s})$ at five different channel bed slopes: 0.001, 0.002, 0.004, 0.009 and

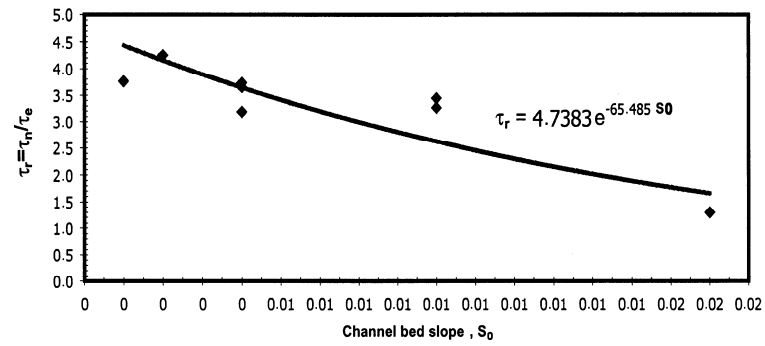

Fig. 6: Boundary shear stress rate at the nose to end of piers base, $\tau_{\mathrm{r}}$, verses channel bed slope, $\mathrm{S}_{0}$

0.016 (Table 1). Based on the results already presented in previous sections, the main findings are as follows:

- In a rectangular channel, three same sizes of elliptical shaped bridge piers are placed exactly in the flow direction and are experimentally examined. The bed shear stress is measured using a Preston tube of $4.7 \mathrm{~mm}$ outer diameter.

- From experimental observations, it can be found that the V-shaped flow separation at horseshoe area is getting longer and wider for higher aspect ratios, $\mathrm{b} / \mathrm{h}$.

- The effect of multiple pairs of secondary flow cells was evident in the perturbations of boundary shear stress for both mild and steep slope channels.

- 4. It appears from the boundary shear stress results that the lateral distributions are very flat at mild slope channels. Thus for a certain flow discharge the active erosion area increases as the Fr number increases or the channel is getting steeper Fig. 2 to 5).

- The averaged values of the shear stress at nose and end base of the piers show that there is a significant reduction in $\tau_{\mathrm{r}}=\tau_{\mathrm{n}} / \tau_{\mathrm{e}}$ values as the flow discharge increases and channel getting steeper Fig. 6. The averaged figure for $\tau_{\mathrm{r}}$ is about 3.6. However, the effect of the pier shape and distances, channel boundary as well as secondary current ells should also be considered.

- The results indicate that the value of $\tau_{\mathrm{r}}$ is not necessarily a constant value for any flow condition, as often assumed in several computational models.

- The results also show that at the free surface, the boundary shear stress is not necessarily zero, as often assumed in certain computational models.

- The information in this paper may prove useful to any computational modelers dealing with channels with a similar shape including bridge piers. The work may also be valuable to river engineers trying to solve erosion and sediment transport problems around the base of piers. 


\section{ACKNOWLEDGEMENTS}

The author would like to acknowledge: The research program is funded by the Department of Research \& Technology Affaires of Urmia University, Urmia, Iran. The experiments were carried out at the Advanced Hydraulics Laboratory of the Department of Water \& Irrigation Engineering, Faculty of Agricultural Engineering, Urmia University.

\section{REFERENCES}

1. Babaeyan-Koopaei K., D.A. Ervine, P.A. Carling and Z. Cao, 2002. Velocity and turbulence measurements for two overbank flow events in river severn, J. Hydr. Engrg., 128 (10): 891-900.

2. Bradshaw, P. and N. Gregory, 1959. The Determination of Local Skin Friction from Observations in the Viscose Sublayer, National Physics Laboratory, Reports and Memoranda, No. 3203, March.

3. Breusers H.N.C., G. Nicollet and H.W. Shen, 1977. J. Hydraulic Res. 15 (3): 211-252.

4. Cunge J.A., F.M. Holly and A. Verway, 1981. Practical Aspects of Computational River Hydraulics, Pitman, London.

5. Knight, D.W. and H.S. Patel, 1985. Boundary shear stress distributions in smooth rectangular duct flow, proc. 2nd Int. symposium on refined flow modeling and turbulence measurements, iowa, USA, Sept., Hemisphere Publishing Co., pp: $122-1$ to $122-10$.

6. Lamb, Horace, 1932. Hydrodynamics, Cambridge University Press.

7. Mohammadi, M., 2000. Cross-sectional shape effects on boundary shear stress distribution in open channels, Proc. 5th Civil Eng. Congress, 8-10 May, Meshed, Iran.

8. Mohammadi, M., 2002. Boundary shear stress distribution in open channels having different cross sections. A Research Report submitted to the Research and Technology Department of Urmia University, Urmia, Iran.
9. Mohammadi, M., 2005. Shape effects on resistance to flow in a $\mathrm{V}$-shaped channel, proceedings int. J. Eng., A Center for Scientific Research, 17 (4): 349-357, June, Tehran, Iran.

10. Mohammadi, M. and D.W. Knight, 1999. Threshold for sediment Motion in V-shaped Open Channels, Proc. 28th IAHR Biennial Congress, 22-27 August, Graz, Austria.

11. Mohammadi, M. and D.W. Knight, 2004. Boundary shear stress distribution in a v-shaped channel. Proceedings first international conference on: Hydraulics of dams and river structures, (HDRS), Esteghlal Hotel, Tehran, pp: 401-410, 26-28 April, Iran.

12. Movahedan, M., 1997. An investigation of hydraulic aspects of hydraulic jump in gradually and sudden enlargement of a rectangular section. MSc thesis, Dept. of Irrigation Eng., Faculty of Agricultural Eng., The University Urmia, Urmia, Iran.

13. Needham D.J. and D.D.L. Zanré, 1996. On the Alluvial Hydraulics of Steady Flow around Bridge Pier, Geophysical and Astrophysical Fluid Dynamics, The Gordon and Breach Publishing Group, September.

14. Patel, V.C., 1965. Calibration of the Preston Tube and Limitations on Its Use in Pressure Gradients, J. Fluid Mechanics, 23 (1): 185-208.

15. Perkins, H.J., 1970. The Formation of Stream wise Vorticity in Turbulent Flow, J. Fluid Mechanics, 44 (4): 721-740.

16. Preston, J.H., 1954. The Determination of Turbulent Skin Friction by Means of Pitot TubeJ. Royal Aeronautical Society, Vol. 58, February.

17. Reynolds A.J., 1965. J. Fluid Mech., 22: 113-133.

18. Ribberink J.A. and J.T.M. Van der Sande, 1985. J. Hydraulic Res., 23: 273-283.

19. Roper A.T., V.R. Schneider and H.W. Shen, 1967. Proc. $12^{\text {th }}$ IAHR Congress, Fort Collins, 3: 151-161.

20. Schlichting H., 1968. Boundary Layer Theory, McGraw-Hill, New York. 